\title{
El traslado de edificios históricos en Galicia: Los ejemplos de San Xoán de Cova, San Estevo de Chouzán y Portomarín
}

\author{
The moving of historic buildings in Galicia: \\ San Xoán de Cova, San Estevo de Chouzán and \\ Portomarín examples
}

\author{
Carla FERNÁNDEZ MARTÍNEZ \\ Universidad de Santiago de Compostela
}

Resumen: En este artículo se analiza una de las prácticas de restauración monumental llevada a cabo durante la segunda mitad del siglo XX, que, aunque fue recurrente, no es suficientemente conocida: el traslado de los edificios históricos. A través del análisis de la documentación en prensa se ha indagado en los ejemplos gallegos de San Xoán de Cova, San Estevo de Chouzán y de Portomarín.

Palabras clave: Patrimonio arquitectónico, Conservación, Galicia, Traslado monumental, Franquismo.

ABSTRACT: In this article we analyse one of the monumental restoration practices used during the second half of the twentieth century that, though it was frequent, it is not widely known: the relocation of historic buildings. By mean of documentation press analysis, Galician examples of San Xoán de Cova, San Estevo de Chouzán and Portomarín.

Keys words: Architectural heritage, Conservation, Galicia, Movement, Francoism.

\section{INTRODUCCIÓN}

Durante la primera mitad del siglo XX, el mal estado de conservación de numerosas construcciones fue in crescendo y se vio agravado por las destrucciones y pérdidas producidas tras los acontecimientos bélicos ${ }^{1}$.

\footnotetext{
${ }^{1}$ La autora es investigadora del Grupo de Investigación "Iacobus" (GI-1907) del Departamento de Historia del Arte de la Universidad de Santiago de Compostela
}

Sin embargo, los cuantiosos daños materiales ocasionados por la Segunda Guerra Mundial pusieron de relieve la necesidad de acordar criterios y procedimientos de intervención

Este texto fue realizado dentro del marco del proyecto de investigación «Encuentros, intercambios y presencias en Galicia entre los siglos XVI y XX» (HAR2011-22899), Ministerio de Economía y Competitividad así como del «Programa de Consolidación e Estructuración de Unidades de Investigación Competitivas» (GRC2013-036). 
urgente en Europa. Hasta entonces se habían aplicado los principios defendidos por los teóricos italianos partidarios de la restauración científica, pero la exigencia de realizar una reconstrucción masiva impuso un nuevo concepto, conocido como restauración crítica, en la que la reconstrucción se entendía como un trabajo de carácter crítico, pero también como un acto creativo ${ }^{2}$. En 1950 la UNESCO publicó el primer número de Museum donde Roberto Pane recogió en su tercer volumen las reflexiones acordadas en una reunión de expertos celebrada en París un año antes ${ }^{3}$. Dichas conclusiones se centraban en dos aspectos principales: la aceptación colectiva de la utilización de materiales y sistemas constructivos modernos, sobre todo en la reconstrucción de cubiertas, estabilización de estructuras y sustitución de la ornamentación pétrea desmantelada ${ }^{4}$. A nivel urbano también se plantearon diversas propuestas, pese a que resultó más complicado llegar a un criterio aceptado por unanimidad, admitiéndose dos alternativas: construir los núcleos que habían sido profundamente alterados tal y como eran previamente, tratando de evitar cualquier innovación, o reconstruir de acuerdo

\footnotetext{
${ }^{2}$ La restauración crítica se fundó en la teoría de Benedetto Croce y fue especialmente defendida por Renato Bonelli, Roberto Pane y Cesare Brandi. Se basaba en la valoración de la riqueza estética, estilística, espacial, estructural y tipológica de la arquitectura. Defendía la restauración, tras elminiar los añadidos no originales que afeaban al edificio y que no le aportaban ningún valor documental. Para estos autores la reconstrucción solo era posible en los casos donde se mantenía su calidad artística, a pesar del estado de conservación en el que se encontraba.

${ }^{3}$ R. PANE, “Considérations sur le Reúnion d'Experts sur les sites et monuments historiques tenue au siège de l'Unesco du 17-21 Octobre 1949", Museum, no 1, III, 1950, pp. 8-89.

${ }^{4}$ A partir de entonces se utilizaron los nuevos materiales, especialmente, el hormigón armado en la reparación de cubiertas y tejados, como ocurrió en la iglesia de Santa Clara en Nápoles, la catedral de Bolzano, la iglesia de San Esteban en Viena o San Pedro de Caen, entre otras. Para mayor információn, véase: B. M. CASTRO FERNÁNDEZ, O descubrimiento do Camiño de Santiago por Francisco Pons Sorolla, Santiago de Compostela, 2010, pp. 26-29.
}

con la estética y la forma de la arquitectura contemporánea.

Si nos centramos en el caso español, la mayor parte de los investigadores coinciden en señalar que durante el Franquismo se produjo un retorno a criterios de restauración obsoletos que ocasionaron la vuelta a prácticas y conceptos desfasados, como el de unidad de estilo, cuyo objetivo era devolver el estado original al edificio. No obstante, es conveniente señalar de antemano que no todas las intervenciones siguieron este criterio, y que algunas de las actuaciones realizadas con anterioridad al régimen también se habían caracterizado por la aplicación de prácticas ajenas a las nuevas teorías y cartas sobre conservación y restauración. Por otro lado, se trató de una actitud generalizada en Europa e, incluso, en países con una larga trayectoria en el campo de la restauración, como Italia, también se realizaron restauraciones estilísticas, se desmontaron numerosos elementos decorativos y se procedió a la reconstrucción mediante la eliminación de partes no homogéneas. Con todo, y pese a que debemos ser cautelosos y no emitir juicios globales, es innegable que durante la posguerra española se propusieron diversas modalidades de intervención muy poco respetuosas, que se solían justificar por el estado ruinoso en el que se encontraban dichos bienes. Quizás una de las menos conocida y estudiada es aquella que abogó por el traslado de ciertas arquitecturas históricas a otros emplazamientos. Esta práctica implicaba sacar de su ambiente al edificio e introducirlo en otro que, además de serle extraño, lo descontextualizaba sin lograr un buen acoplamiento ${ }^{5}$. Aunque fueron numerosas las actuaciones que llegaron a materializarse, otras no pudieron efectuarse ante el elevado coste que acarreaban, $y$, sobre todo, por el rechazo de la población local y de sectores intelectuales sensibilizados con la protección del patrimonio.

\footnotetext{
${ }^{5}$ Sobre el traslado de edificios históricos durante el franquismo, puede resultar de interés: E. MORAIS VALLEJO, "Traslado de edificios históricos. El caso de León durante la etapa franquista", De Arte, nํ1, 2002, pp. 113-137.
} 
Limitándonos al estudio del caso gallego, comprobamos que fueron varias las propuestas de desmontar, piedra a piedra, algunos de sus monumentos para ubicarlos en las principales urbes de la región, con la pretensión de contribuir a su embellecimiento ${ }^{6}$. Sin embargo, conviene resaltar que en las décadas centrales del siglo XX se desmantelaron otros edificios para favorecer el "progreso" y la mejora de las infraestructuras. Precisamente, en este artículo trataremos de analizar a través de la rica documentación de la prensa de la época los traslados de tres ejemplos de la provincia de Lugo, en Galicia.

Tras la Guerra Civil, España se encontraba en una situación de pobreza y deterioro que afectó tanto a su población como a su patrimonio material. Por ello, uno de los primeros objetivos del gobierno franquista fue emprender un plan de revitalización de Obras Públicas, para lo que se creó la Dirección de las Regiones Devastadas que tenía como objetivo recuperar algunas de las arquitecturas más singulares y construir más y mejores infraestructuras. Las medidas que se adoptaron trataron de incrementar los enlaces de la nación y empujar el desarrollo de la industria, asegurando un mayor suministro de energía eléctrica que hiciese posible el autoabastecimiento, gracias, como veremos, a la construcción de numerosos pantanos. Este afán de desarrollo, para recuperar el tiempo perdido, tuvo sus repercusiones negativas en el patrimonio cultural y, en no pocas ocasiones, se llegaron a sacrificar numerosos edifi-

${ }^{6}$ Tal fue el caso de los monasterios de Santa María de Monfero y Santa María de Montederramo que se pretendieron trasladar a las ciudades de A Coruña y Vigo, respectivamente. Para mayor información véase C. FERNÁNDEZ MARTÍNEZ, "La memoria olvidada. Una aportación a la historia contemporánea de Santa María de Monfero y Santa María de Montederramo", Anuario Brigantino (en prensa); ÍDEM, "La memoria en sepia. Una aportación a la historia contemporánea del monasterio de Santa María de Montederramo", en J. M. MONTERROSO MONTERO, E. FERNÁNDEZ CASTINEIRAS (coords.), Entre el agua y el cielo: el patrimonio monástico de la Ribeira Sacra, Santiago de Compostela, 2012, pp. 323-339. cios e incluso poblados enteros para favorecer la instalación de nuevos equipamientos.

A mediados de la década de los años cincuenta se proyectaron en las cuencas de los ríos Miño y Sil varias presas hidroléctricas que pusieron en peligro algunos monumentos de origen medieval, como los templos de San Xoán da Cova (Fig. 1) y San Estevo de Chouzán (Fig. 2). De todas formas, el caso más alarmante y conocido no se limitó a una única arquitectura, sino que afectó a la totalidad de un pueblo: nos referimos al antiguo Portomarín (Fig. 3).

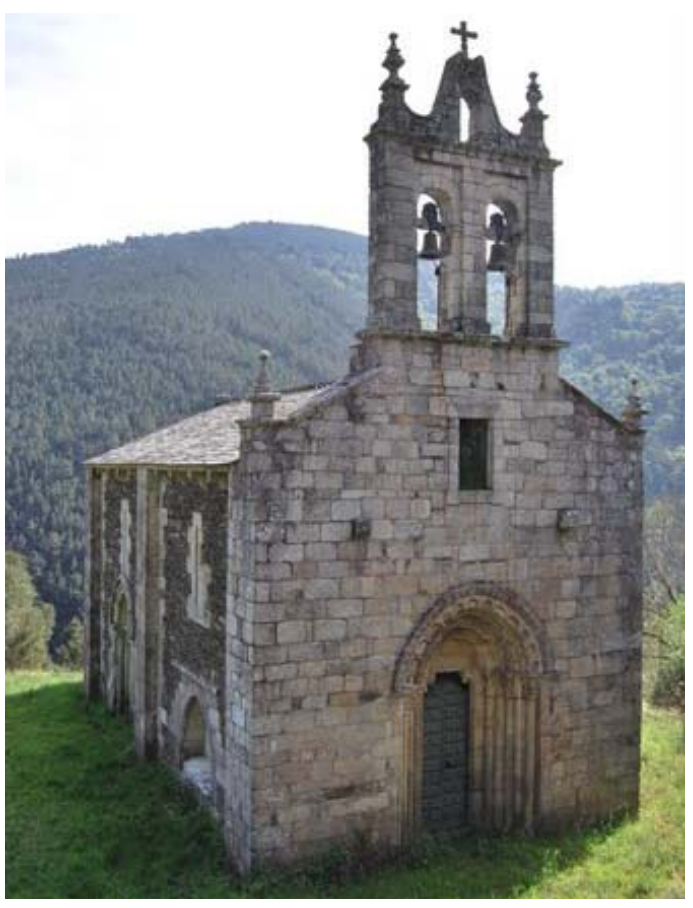

- Fig. 1. Iglesia de San Xoán de Cova en su ubicación actual. Fotografía de la autora.

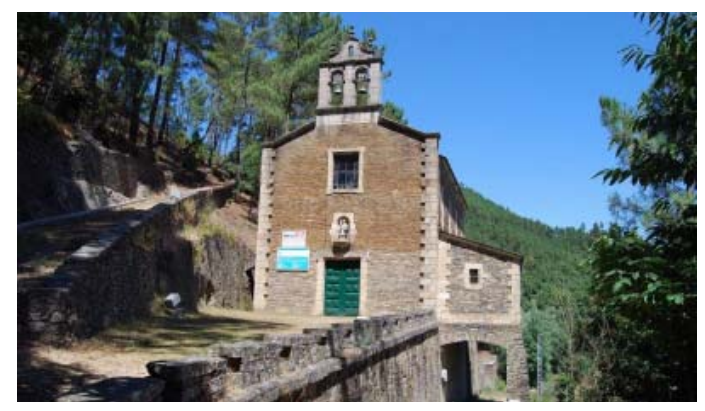

- Fig. 2. Iglesia de San Estevo de Chouzán en la actualidad. Fotografía de la autora. 


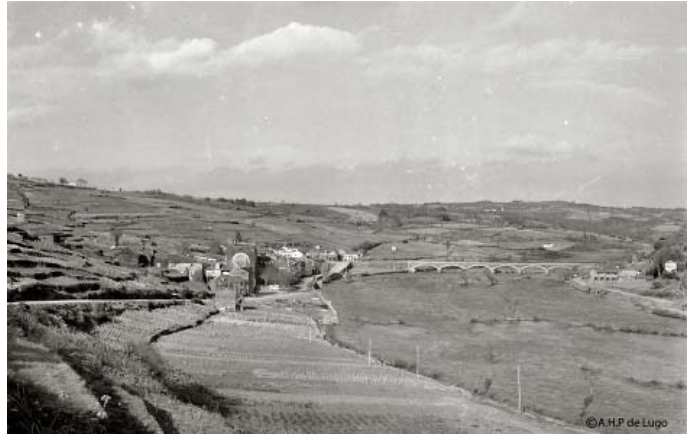

- Fig. 3. Fotografía de Portomarín antes de su traslado. Archivo Histórico Provincial de Lugo (AHPLu). Colección fotográfica de Juan José, signatura 18-059-05.

\section{UN ANTECEDENTE DE LOS CASOS GALLEGOS DE TRASLADOS DE MO- NUMENTOS: LA IGLESIA DE SAN PEDRO DE LA NAVE}

"El agua embalsada del Esla va a tragarse a un humilde pueblecito de Castilla. La tierra en este leve y generoso rincón, para que la industria exalte y alumbre otras dilatadas llanuras, se presta resignada a hundirse en el agua, en la quietud de su remanso, ocultándose para siempre a la luz del sol"7.

Con estas palabras aludía el diario $\mathrm{ABC}$ al trágico desenlace que le esperaba al pueblo de la Pueblica, caracterizado por la presencia de la singular iglesia de San Pedro de la Nave. La idea de levantar allí la presa de Ricobayo se había planteado a finales de 1919; su construcción implicaba la desaparición de la pequeña población y de la iglesia, pero pronto surgieron ciertas voces preocupadas ante la posible pérdida de uno de los vestigios más destacados de arquitectura visigoda. Según Esteban Chaparría ${ }^{8}$, fue el director del Museo de Zamora, Severiano

${ }^{7}$ F. MENDIZABAL, “La iglesia visigoda de San Pedro de la Nave y los saltos del Duero", $A B C$ de Sevilla, 07-12-1930, p. 15.

${ }^{8}$ Este autor ofrece un análisis detallado del templo y del proceso de traslado. J. ESTEBAN CHAPARRÍA y M. P. GARCÍA CUETOS, Alejandro Ferrant y la conservación monumental en España (1929-1939), León, 2007, pp. 304-313.
Ballesteros, el primero que inició los trámites para proteger San Pedro, solicitando la intervención de la Comisión de Monumentos de Zamora, quien, a su vez, informó a la Academia de la Historia y a la de Bellas Artes. La primera de ellas se mostró opuesta tanto a la idea del traslado como a la desaparición del templo, puesto que, siguiendo los planteamientos que se estaban difundiendo en Europa, consideraba que el monumento y su entorno eran indisociables. Como alternativa, proponía desplazar la presa a otro lugar o construir un dique para proteger la iglesia. Por su parte, la Academia de Bellas Artes argumentaba que se debía intentar salvar el templo, pero aceptaba como un mal menor el traslado si esa era la única opción posible para impedir la desaparición del monumento?.

Aunque el proyecto se demoró unos años, con la llegada de Rafael Benjumea al Ministerio de Fomento se impulsó el desarrollo de las obras públicas en España y se activaron las concesiones de los saltos del Duero $^{10}$. El Real Decreto- Ley de agosto de 1926 otorgó a la Sociedad Hispano-Portuguesa de Transportes Eléctricos la concesión de los tramos españoles ${ }^{11}$, entre los que figuraba el aprovechamiento del río Esla, con un ensanche y una central de pie en Ricobayo. Sin embargo, en su artículo 15 el Decreto señalaba que:

"el concesonario queda obligado a trasladar al lugar que le ordene el Ministerio de Instrucción Pública y Bellas Artes o sus delegados el templo visigodo de San Pedro de la Nave, declarado Monumento Nacional por Real Orden el 22 de abril de 1912".

Unos años más tarde, el ingeniero Vicente Machimbarrena publicó diversas reseñas sobre los problemas que podía acarrear

${ }^{9}$ Ibídem.

${ }^{10}$ F. SAENZ RIDRUEJO, Los ingenieros de caminos, Madrid, 1993, pp. 186-194.

${ }^{11}$ Gaceta de Madrid, 24-08-1926, consultado el 23 de octubre del 2014. URL: http://www.boe.es/datos/pdfs/ BOE/1926/236/A01155-01159.pdf. 
su desmonte ${ }^{12}$, proponiendo dos soluciones: $\mathrm{u}$ optar por desmontarlo y reedificarlo en otro lugar o dejar que el edificio se sumergiese.

Entre el 1930 y el 1932 se efectuó el traslado del templo por iniciativa de Manuel Gómez Moreno, arqueólogo e historiador ${ }^{13}$, según un proyecto realizado por el arquitecto Alejandro Ferrant ${ }^{14}$. Tras plantearse la posibilidad de levantarlo nuevamente en Zamora -solución que desvirtuaría la construcción al situarla en un entorno muy diferente al primitivo-, se decidió llevarlo al Campillo, una localidad cercana que carecía de iglesia parroquial. Se trató de una reconstrucción en estilo con la que Ferrant pretendió recuperar el edificio visiogodo tal y como había sido concebido en origen, eliminando los añadidos posteriores a la fábrica primitiva como la

${ }^{12}$ V. MACHIMBARRENA, "Edificios inundados", Colección de artículos de información. Cuaderno II, enero y marzo 1930, pp. 26-29.

13 Sobre su figura, puede resultar de interés: $M$. P. GARCÍA CUETOS, "La renovación de la Historia de la Arquitectura y del Arte en las primeras décadas del siglo XX: Manuel Gómez Moreno", en M. P. BIEL IBÁÑEZ (coord), Lecciones de los maestros: aproximación histórico-crítica a los grandes historiadores de la arquitectura española, Zaragoza, 2011, pp. 125-158.

${ }^{14}$ Para aproximarse a la obra de este arquitecto: J. ESTEBAN CHAPARRÍA y M. P. GARCÍA CUETOS, Op. Cit.; J. ESTEBAN CHAPARRÍA, "Alejandro Ferrant Vázquez y Luis Menéndez-Pidal Álvarez: secuencia de unas intervenciones contrapuestas en las catedrales de Santiago de Compostela y Oviedo", en G. A. RAMALLO ASENSIO (coord.), El comportamiento de las catedrales españolas: del Barroco a los historicismos, Murcia, 2003, pp. 131-148; M. P. GARCÍA CUETOS, “Historia de la arquitectura y restauración. Alejandro Ferrant Vázquez y Manuel Gómez-Moreno: la aplicación del método del Centro de Estudios Históricos a la restauración monumental", Loggia. ArquitecturaERestauración, no 21, 2008, pp. 8-25; ÍDEM, "Las intervenciones en los monumentos mudéjares de Castilla-León. De Alejandro Ferrant a Luis Menéndez-Pidal", en Actas del XI Simposio Internacional de Mudejarismo, Teruel, 2009, pp. 17-35; ÍDEM, “La labor de Alejandro Ferrant Vázquez en Cataluña durante el primer franquismo", en M. P. GARCÍA CUETOS, M. E. ALMARCHA, y A. HERNÁNDEZ MARTÍNEZ (coords.), Restaurando la memoria: España e Italia ante la recuperación monumental de posguerra, Gijón, 2010, pp. 67-92. espadaña y el porche. Pese a ello, fue un traslado modélico, tanto por su carácter pionero como por su objetivo: salvar un monumento de la euforia modernizadora de las primeras décadas del siglo XX.

LA CONSTRUCCIÓN DEL EMBALSE DE LOS PEARES Y EL TRASLADO DE LAS IGLESIAS DE SAN XOÁN DE COVA Y SAN ESTEVO DE CHOUZÁN

Fuerzas Eléctricas del Noroeste S. A. (FENOSA) se creó el 23 de agosto de 1943, bajo la presidencia de Pedro Barrié de la Maza. Con ella se inició la época de los grandes embalses y pantanos que impulsó el Gobierno Franquista y que tuvieron a Galicia como uno de los escenarios predilectos ${ }^{15}$. El río Miño, el de mayor longitud de la región, se presentó como un marco ideal para la proyección de los embalses más importantes: Belesar, los Peares, Velle, Castrelo y Frieira. Precisamente, la construcción de los dos primeros ocasionó el traslado de varios edificios que habían sido declarados Monumentos Histórico-Artísticos.

Los Peares, concluido en 1955, recorre el territorio lucense, bañando los municipios de Carballedo, Pantón, Chantada y Saviñao. Su construcción afectó a dos templos de origen románico -San Xoán de Cova y San Estevo de Chouzán- a los que decidieron trasladar a un enclave próximo tras valorarse su importancia histórico-artística.

“La iglesia de San Juan de Coba, del Ayuntamiento de Carballedo, provincia de Lugo, cuya construcción data de fines del siglo XII, conserva íntegra la planta románica, que ni por su forma ni por sus proporciones difiere de otros muchos ejemplares del Románico rural de la región y la finura de sus elementos decorativos, poco comunes en las

\footnotetext{
${ }^{15} \mathrm{Al}$ respecto puede resultar de interés: M. P. de TORRES LUNA, A. PAZOS LABRADOR y J. M. SANTOS SOLLA, Los embalses de Fenosa y la Geografía de Galicia, A Coruña, 1988.
} 
iglesias de su clase, la hacen singularmente agradables"16.

Con estas líneas se iniciaba el Decreto para la Declaración de Monumento Histórico-Artístico de la iglesia de San Xoán de Cova, de Octubre de $1950^{17}$. Este templo románico del arciprestazgo de Chantada-Lugo se encuentra en el municipio de Carballedo, uno de los que resultó más afectado por el embalse (Fig. 1). Se trata de una iglesia románica, datada en torno al segundo cuarto del siglo XIII, que había pertenecido a un convento de Benedictinas, y que se desmontó para evitar que quedase anegada por las aguas.

Los estudios preliminares para efectuar tal obra fueron realizados por los Técnicos de la Primera Zona del Servicio de Defensa del Patrimonio Artístico Nacional, el Comisario de Defensa del Patrimonio Artístico Nacional, el Comisario de la zona Manuel Chamoso Lamas ${ }^{18}$ y los arquitectos Luis Menéndez Pidal y Pons-Sorolla.

Una de las cuestiones más acuciantes era decidir cuál debía ser su nuevo emplazamiento. Tras proponerse diversas alternativas, se optó por un terreno próximo que desvirtuaba lo menos posible el entorno del

${ }^{16}$ Decreto de 16 de Octubre de 1950 por el que se declara monumento histórico-artístico la iglesia de San Juan de Coba del Ayuntamiento de Carballedo (Lugo), consultado el 13 de septiembre del 2014. URL: http://www.boe.es/datos/ pdfs/BOE/1950/319/A05301-05301.pdf.

${ }^{17}$ Sobre la iglesia de San Juan de Coba, véase: J. RAMÓN Y FERNÁNDEZ OXEA, “Jornadas románicas por tierras de Lugo", Archivo Español de Arte, Tomo XVI, 1943, pp. 239-263; L. RIOS RAMOS, "San Xoán da Cova: A Cova, Carballedo, Lugo", en F. RODRÍGUEZ IGLESIAS (dir.), Mosteiros e conventos da Península Ibérica. Galicia, A Coruña, 2008, Tomo III, pp. 206-215; R. YZQUIERDO PERRÍN, La arquitectura románica en Lugo, A Coruña, 1983, pp. 140-143; R. YZQUIERDO PERRÍN y C. MANSO PORTO, C., "Arte medieval (2)”, en Galicia. Arte, vol. XI, A Coruña, 1993, p. 242.

${ }^{18}$ Para mayor información sobre las intervenciones de Chamoso Lamas en el Miño, véase: R. YZQUIERDO PERRÍN, "El río Miño vía de difusión artística: de Portomarín a Os Peares", en F. S. LÓPEZ GÓMEZ (dir.), Lugo no obxetivo de Manuel Chamoso Lamas, Lugo, 1995, pp. 65-86. monumento, evitaba su profunda descontextualización y estaba cerca de los núcleos de población.

Pons-Sorolla fue uno de los arquitectos que más contribuyó a la conservación del patrimonio gallego durante esa época, pero nunca se había enfrentado a una intervención de tales características ${ }^{19}$; sin embargo, no fue la única y poco después tuvo que afrontar otra de mayor complejidad. Pese a su cautela, se efectuó una depuración formal y se realizaron actuaciones menores, como el desencalado de los muros, la eliminación del retablo y la reordenación del mobiliario litúrgico. Se mantuvo la portada de doble arquivolta, que reemplazó el antiguo acceso del costado norte, pero en el lado del mediodía se construyó una nueva sacristía y se cegó el hueco del ábside que lo comunicaba con una capilla adosada. Las obras se prolongaron hasta octubre de 1954, dado que tuvieron que ser interrumpidas en numerosas ocasiones por las inclemencias metereológicas.

Como anticipamos, la construcción de los Peares implicó la desaparición de otro templo románico: San Estevo de Chouzán, también en el municipio de Carballedo (Fig. $2)^{20}$. La iglesia había sido declarada Monu-

\footnotetext{
${ }^{19}$ Sobre la obra de Francisco Pons-Sorolla en Galicia, véase: B. M. CASTRO FERNÁNDEZ, Op.cit.; ÍDEM, Francisco Pons-Sorolla y Arnau. Arquitecto restaurador: sus intervenciones en Galicia, Santiago de Compostela, 2007.

${ }^{20}$ Sobre esta iglesia, véase: J. DELGADO GÓMEZ. "Iglesia de San Esteban de Chouzán" en Arte románico, Lugo y su provincia, Lugo, 1996, T. IV, pp. 41-59; T. MOURE PENA, “Revisión histórico-documental en torno al antiguo monasterio benedictino de San Esteban de Chouzán", Boletín do Museo Provincial de Lugo, no 12, 2005, pp. 125-170; ÍDEM, “San Estebo de Chouzán en el contexto del arte gótico: revisión de su proceso cronoconstructivo" en Ruta cicloturística del Románico-Internacional, Pontevedra, 2009, pp. 237-246; G. NÚÑEZ DÍAZ, “Chouzán y sus señoras abadesas: monjas y conventos en las narraciones de Cunqueiro", Lucvs, no ${ }^{\circ}$ 1, 1993, pp. 78-81; R. PICHEL GÓTERREZ, Fundación e primeiros séculos do mosteiro bieito de Santo Estevo de Chouzán, A Coruña, 2009; J. RAMÓN Y FERNÁNDEZ OXEA, “San Esteban de Chouzán y sus pinturas murales", Separata de Archivo Español de Arte, Madrid, 1944; R. YZQUIER-
} 
mento Histórico-Artístico el mismo año que San Xoán de Cova ${ }^{21}$. La mayor parte de los autores sitúa su cronología a finales del siglo XII o principios del XIII y se trata del único vestigio de un monasterio levantado en el siglo X. Al igual que en el caso anterior, Francisco Pons Sorolla fue el responsable de diseñar el desmonte y elegir un emplazamiento adecuado: un monte de gran declive, conocido como "O Salgueiral", próximo a los dos pueblos que integraban la parroquia de Chouzán.

El templo tenía la peculiaridad de presentar una planta en cruz latina, inusual en el Románico rural gallego, que fue modificada al organizarse en una sola nave rectangular con cuatro tramos. Se optó por conservar y trasladar las pinturas murales y otras piezas molduradas que decoraban el ábside, pero el resto de los elementos -la nave, la sacristía, el despacho parroquial, el baptisterio- se construyeron ex novo, intentando reproducir su traza original, amparándose en que:

“No encontrándose el resto del templo en su estado originario ni conteniendo sus fábricas valores artísticos que aconsejen su conservación, la Dirección General de Bellas Artes dispuso oportunamente fueran arrancadas las pinturas y entregadas al Obispado de Lugo para su conservación así como todos aquellos elementos decorados que constituyen documento histórico-arqueológico de valor para la historia del Arte lucense" 22 .

El ábside se reconstruyó de manera íntegra y en la fachada principal se mantuvieron los esquinales de sillería y la espadaña barroca. Con todo, lo más delicado con-

DO PERRÍN, La arquitectura románica en Lugo, A Coruña, 1983, pp. 182-185.

${ }^{21}$ Decreto del 16 de Octubre por el que se declara Monumento Histórico-Artístico el Monasterio de Chouzán, en el Ayuntamiento de Carballedo (Lugo), consulado el 23 de agosto de 2014. URL: http://www.boe.es/datos/pdfs/ BOE/1950/319/A05301-05301.pdf.

\footnotetext{
${ }^{22}$ La documentación relativa a este traslado se cus-
} todia en el Archivo Pons Sorolla y está en parte publicada en: B. M. FERNÁNDEZ CASTRO, Francisco PonsSorolla y Arnau. Arquitecto restaurador..., pp. 395-396. sistió en extraer las pinturas murales, tarea que llevó a cabo Antonio Llopart. Esta actuación implicó la edificación de un nuevo ábside que complicó el proceso e hizo necesario el reajuste y retoque de las pinturas.

Tras estas dos intervenciones, pioneras en Galicia, Pons-Sorolla se preparaba para una obra que resultó mucho más compleja y, sobre todo, polémica: el traslado del poblado de Portomarín, del que nos ocuparemos seguidamente.

\section{LA CONSTRUCCIÓN DEL EMBALSE DE BELESAR Y EL TRASLADO DE LA VILLA DE PORTOMARÍN}

Portomarín, cabeza del Ayuntamiento homónimo de la provincia de Lugo, se encontraba situado hasta los años sesenta del siglo pasado en la margen derecha del río Miño (Fig. 3). Sus primeras referencias históricas aluden a época romana, siendo su testimonio más significativo el puente que sobrevivió hasta época medieval. Sabemos que a principios del siglo $X$ la villa $y$ los centros monásticos de Santa Marina, San Salvador y Santa Cruz pertenecían al padre de San Rosendo, Don Gutiérrez Menéndez, aunque a finales de la centuria se integró en la Iglesia de Santiago. Su importancia creció considerablemente en el siglo XII, gracias al empuje que experimentaron las pereginaciones compostelanas, formando parte del Camino francés, como una de sus etapas más importantes que aparecía recogida en el Códice Calixtino. Esa trascendencia como punto obligado del Camino potenció la relevancia del Hospital de Peregrinos, así como la construcción de la iglesia de San Juan. Con posterioridad, Alfonso IX de León reafirmó la donación de la villa a la orden de Santiago y Enrique IV le concedió diversos privilegios para que sus comendadores conservasen en buen estado el hospital, la iglesia y el Camino de Peregrinación ${ }^{23}$.

\footnotetext{
${ }^{23}$ Para un mayor conocimiento de la historia de Portomarín, véase, entre otros: A. FERNÁNDEZ LÓPEZ, Portomarín: anacos da súa historia, Lugo, 2013; F. OCAÑA EIROA, Monografías do Patrimonio Monumental
} 
Desde el punto de vista morfológico, la villa se encontraba dividida en dos barrios, cada uno situado en una margen del río Miño: el de San Pedro y el de San Nicolás. Era en el último donde se encontraba el antiguo hospital de los peregrinos, levantado en 1126 y reconstruido en 1484. Además, en el burgo de San Pedro existían otros dos centros hospitalarios, destacando el de San Lázaro. Portomarín contaba con edificios relevantes como la Casa de la Encomienda, destinada al descanso del caminante, y diversas arquitecturas civiles con blasones de los siglos XVI y XVIII. Por lo que respecta a su patrimonio religioso, sobresalían las iglesias de San Juan y San Pedro y la capilla de Santiago.

El pueblo fue declarado conjunto histórico-artístico el 8 de febrero de 1946, pero a principios de los años cincuenta la idea de construir la presa de Belesar anunciaba su destino trágico. Inicialmente, se proyectó una presa menor, que permitiría salvarlo, pero finalmente se optó por una de 135 metros, que implicaba que el poblado fuese anegado por completo. $Y$ es que, como ya se anticipó, durante los años 50 y 60 el ansia de "progreso" no dudó en sacrificar enclaves de interés histórico, artístico y humano. La construcción del embalse se inició en 1957, pero dos años antes la prensa nacional ya apuntaba el desenlace final para los habitantes y el patrimonio de la villa ${ }^{24}$ :

"Como un clarinazo detonante se ha paseado por España la noticia de que Puertomarín, la villa que está considerada como una auténtica joya de la Edad Media gallega, va a ser sepultada por las aguas de un gigantesco embalse".

La reseña continuaba incidiendo en la importancia histórica de Portomarían y señalaba las alternativas para evitar su pérdi-

Galego. San Xoán de Portomarín, A Coruña, 1987; G. PAZ LÓPEZ, Portomarín. Monografía Geográfica de una villa medieval, Lugo, 1961; J. TRAPERO PARDO, Lugo/Espana, Madrid, 1970.

${ }^{24}$ A. QUINTANA PEÑA, “La desaparición de Puertomarín”, La Vanguardia Española, 03-04-1955, p. 6. da, puesto que, en palabras de su autor, esta "representa un tremendo golpe espiritual para sus habitantes a quienes envuelve la natural desesperación" 25 .

Solo unos meses después, el mismo periódico dedicó un extenso reportaje a la villa bajo el titular de "Portomarín, posible víctima del progreso" ${ }^{26}$. Se trató de uno de los casos más emblamáticos no solo en España, sino también en Europa y contó con la oposición de sus habitantes y de numerosos intelectuales de la época. Pese a haber sido declarado conjunto histórico-artístico y poseer importantes bienes patrimoniales, como la iglesia-fortaleza de San Juan (Figs. 4 y 5) y la iglesia de San Nicolás, la única alternativa que se propuso fue su traslado a un enclave próximo, sin plantearse la posibilidad de variar el trazado del embalse. Pronto se formó un Gabinete Técnico de Fenosa que redactó un proyecto para la realización del embalse y encargó a Pons Sorolla y a Manuel Moreno el estudio del desmonte de los edificios más significativos.

Pons Sorolla se propuso evitar la reconstrucción mimética del poblado, considerando, además, que el traslado de los edificios a otro lugar podía ocasionar la pérdida de elementos importantes, y así manifestaba que $^{27}$ :

"La historia científica del Monumento termina con el estado de su conocimiento al ser desmontado. A partir de ese momento se pierde toda posibilidad de estudio a la luz de futuras técnicas y ello constituye responsabilidad tan grave para un restaurador consciente que no puede menos de considerar como profanación su temeraria labor".

Por otro lado, el arquitecto insistía en que, aunque el desmontaje se realizase con el máximo criterio científico, tal intervención

${ }^{25}$ Ibídem.

${ }^{26}$ A. QUINTANA PEÑA, "Portomarín, posible víctima del Progreso", La Vanguarida Española, 10-07-1955.

${ }^{27}$ Citado por: B. M. FERNÁNDEZ CASTRO, Francisco Pons-Sorolla y Arnau. Arquitecto restaurador..., p. 500 . 
podría ocasionar la pérdida de sus características constructivas y ambientales.

Finalmente, se decidió trasladar solo aquellas construcciones más significativas, esto es: la iglesia de San Juan y la capilla de Santiago -que se montaron íntegramente- y la de San Pedro -de la que solo se reconstruyó la portada románica y el mausoleo de la familia Pimentel ${ }^{28}$. Junto a ellos se reconstruyó la antigua fuente del siglo XVIII, algunos blasones y los pilares soportalados de la conocida como "Casa del General". La idea de levantar un nuevo poblado era la única alternativa para conservar estas construcciones y, sobre todo, era necesario desde el punto de vista humano, puesto que, en efecto, con la presa los habitantes del pueblo perdieron sus viviendas y terrenos. Se trataba de una población dedicada, sobre todo, a la agricultura y, por ello, la elección del nuevo emplazamiento tuvo como prioridad buscar zonas aptas para el cultivo. De ahí que se optase por el monte del Cristo, a 467 metros de altitud, que estaba separado del Viejo Puertomarín por el arroyo de Tormes ${ }^{29}$.

Para su trazado, el arquitecto se rigió por dos objetivos principales: cuidar la perspectiva de los monumentos trasladados y mantener la visión de conjunto. Así, se decantó por un trazado centrípeto, presidido por la Plaza mayor, donde se situaron los edificios desmontados. En cuanto a las calles, se adaptaron todo lo posible a la morfología del terreno y se incluyó como elemento nuevo el soportal para unificar y dotar de un sentido homogéneo al pueblo.

${ }^{28} \mathrm{Al}$ respecto puede resultar de interés: B. M. CASTRO FERNÁNDEZ, "Ordenación de conjuntos medievales en el camino de Santiago: traslado y restauración de Portomarín", Ad Limia, no 1, 2010, pp. 201-237; J. VARELA VILLAMOR, Desmonte, traslado y montaje de las iglesias fortaleza de San Juan y la de San Pedro, arco del puente romano y capilla de Santiago del pueblo de Portomarín, salvándose de su anegamiento por el rio Miño, en Belesar, Lugo, 1970.

${ }^{29}$ F. OCAÑA EIROA, “Traslado y restauración de la iglesia románica de San Juan de Portomarín", Abrente. Boletín de la Real Academia de Bellas Artes de Nuestra Señora del Rosario, no 38-39, 2006-2007, p. 24.
De la fábrica de la iglesia de San Pedro se trasladó únicamente su portada y el mausoleo Pimentel. Esta decisión se fundamentó en el escaso valor del resto de los elementos y también en razones económicas, debido a los elevados costes que suponía la obra. Se ubicó al final de la calle principal para crear un eje privilegiado, sin restar protagonismo a la iglesia de San Juan, que se situó en la Plaza Mayor. Precisamente, fue a este último templo al que se le confirió una mayor singularidad. Su traslado constituyó uno de los hitos de la historia de la restauración española. Se trató de devolverle su forma originaria y para ello se recuperó su parte superior fortificada, eliminándosele el absidiolo que tenía pegado al ábside. Se construyó un remate almenado que se completó con dos torres, una en cada esquina. La finalidad era enfatizar su carácter románico $\mathrm{y}$, por ello, se eliminaron los añadidos posteriores. En cuanto a la capilla de Santiago la decisión de su traslado estuvo motivada por su carácter remomerativo del culto jacobeo.

El traslado se inició en 1960 y finalizó en 1964; como anticipábamos fue uno de los casos más singulares de España y tuvo una gran repercusión internacional. Desde el inicio fueron numerosas las opiniones a favor y en contra. La noticia no fue bien recibida por los habitantes del pueblo que perdieron sus hogares y, en cierta medida, su trabajo, como señaló la prensa de la época ${ }^{30}$ :

"Es más que seguro que este hecho significativo del progreso de nuestros tiempos- lleve una dosis de amargura, de tristeza y evocadora nostalgia al corazón de muchos de los que allí nacieron y allí tenían formado su hogar, un hogar transmitido de padres a hijos, de unas generaciones a otras, para los que cada rincón solitario, cada piedra de sus viejas iglesias, de sus blasonados palaciones eran como testigos mudos del paso de muchas generaciones (...) La historia registrará los hechos. Cuando pasen los años contem-

${ }^{30}$ L. CONDE RIVERA, "El embalse de Belesar sepulta la histórica villa de Puertomarín", $A B C, 23-01-$ 1962, pp. 12-13. 
plaremos una Galicia poderosamente industrializada a base de sus grandes saltos, sus magníficos pantanos, y el humo de las chimeneas de sus fábricas será como un heraldo de vida nueva, mientras el zumbido de sus motores ensaya un alegre canto al trabajo. Puertomarín, más débil en la lucha, sucumbe, así, "víctima" de los kilovatios..."

Como era de esperar la prensa de Galicia también incluyó numerosas reseñas de este episodio, incluyendo, en algunos casos, declaraciones del propio Pons-Sorolla ${ }^{31}$. En 1963, año en el que Franco visitó el nuevo poblado, se incluyeron titulares como "Una aldea gallega resucita de las aguas" ${ }^{\prime 2}$. La noticia hacía alusión a cómo la retirada de las aguas del embalse con motivo de una limpieza o de alguna reparación de la central, dejó a la luz los restos del antiguo Portomarín cuyo centro histórico parecía una ciudad bombardeada.

\section{NOTA FINAL}

Para entender la aceptación del desmantelamiento, piedra a piedra, de los ejemplos comentados, como una de las "posibles soluciones" ante los problemas que planteaba su conservación, debemos recordar las coordenadas culturales y políticas de la época. En la actualidad, tanto la teoría de la restauración como los mecanismos legales están de acuerdo en que no se deben trasladar los monumentos, no solo por el carácter ilícito de tal actuación sino también, como muy bien apuntó Cesare Brandi, porque "el monumento, desmontado y reconstruido en otro lugar se degrada, siendo un falso de sí mismo"33. Brandi señalaba que solo era legítima la recomposición de un monumento en caso de que no se pudiese garantizar su sal-

\footnotetext{
${ }^{31}$ ANÓNIMO, "El traslado de los monumentos de Puertomarín comenzará antes de primavera. Declaraciones del Señor Pons-Sorolla", El Progreso, 12-01-1960, p. 1.

${ }^{32}$ ANÓNIMO, "Una aldea gallega resucita de las aguas", $A B C, 30-10-1963$, p. 65

${ }^{33}$ C. BRANDI, Teoría de la restauración, Madrid, 1999, p. 78.
}

vaguarda de otro modo, pero esta siempre se debía realizar en su lugar originario ${ }^{34}$.

Conviene resaltar que el proyecto de traslado de estas iglesias coincidió cronológicamente con la época de gran especulación inmobiliaria, que produjo la demolición de muchos edificios. Las décadas centrales del siglo XX fueron nefastas para la conservación y valoración de nuestro patrimonio histórico-artístico y, a la ya comentada ausencia de una legislación, se sumaron la politización de la cuestión arquitectónica y las fatales consecuencias del acelerado crecimiento urbano. Reconociendo, como ya se ha señalado, que no todas las restauraciones de estas décadas fueron estilísticas ni que todas las intervenciones que se habían realizado con anterioridad respondían a concepciones modernas y menos agresivas, debemos manifestar que un buen número de las actuaciones se caracterizaron por la falta de rigor científico e histórico y por el retorno a unas posturas tradicionalistas que buscaban ensalzar el nuevo Estado ${ }^{35}$. El contexto político español en la década de los sesenta, pese a la tímida "liberalización" que posibilitó la actividad de editoriales que permitirían una gradual recuperación de la cultura del exilio y la entrada de nuevas corrientes de pensamiento, seguía impidiendo el desarrollo de un debate abierto y libre que afectó también al propio concepto de conservación.

La mayor parte de las investigaciones que han analizado la práctica de la restauración durante esta época coinciden en señalar que el traslado de los monumentos se consideró como una de las modalidades más recurrentes para "conservar" la arqui-

${ }^{34}$ Ibídem, pp. 77-80.

${ }^{35}$ Entre las publicaciones que han abordado y estudiado la conservación y restauración durante el Franquismo cabe destacar, entre otras: I. CASAR PINAZO y J. ESTEBAN CHAPARRÍA, Bajo el signo de la victoria. La conservación durante el primer franquismo, Valencia, 2008; M. P. GARCÍA CUETOS, E. ALMARCHA y A. HERNÁNDEZ MARTÍNEZ, Restauración, reconstrucción e identidad nacional en la posguerra europea, Gijón, 2010; ÍDEM, Historia, restauración y reconstrucción monumental en la posguerra europea, Madrid, 2012. 


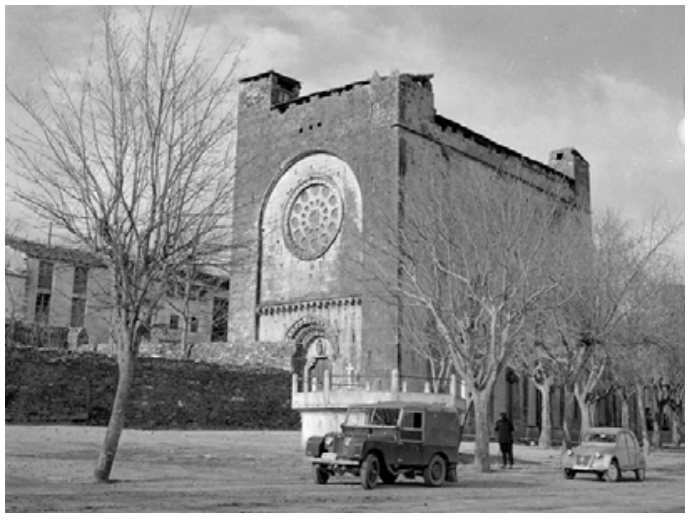

- Figura 4. Iglesia de San Juan antes de su traslado. AHPLu. Colección fotográfica de Juan José, signatura 18-061-01.

tectura, pese a que hubo muchas opiniones contrarias a tales prácticas ${ }^{36}$. Como ha señalado, entre otros, Fernández Castro los factores que derminaron el desplazamiento de bienes culturales fueron diversos ${ }^{37}$; en este caso hemos tratado de analizar tres ejemplos que respondieron a la política de reconstrucción franquista y a su deseo por construir pantanos. Sin embargo, también hubo otras motivaciones, así, se realizaron desmontes parciales de ciertos edificios significativos durante la Guerra Civil para evitar su pérdida y reconstruirlos cuando terminase el conflicto, tal y como ocurrió con la recogida

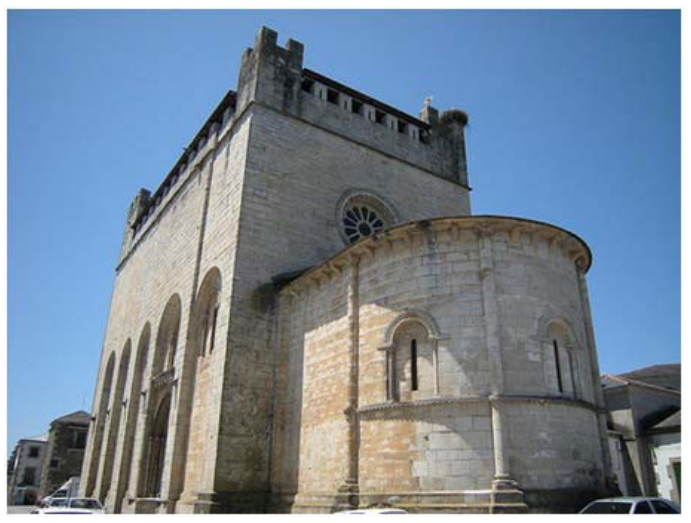

- Figura 5. Iglesia de San Juan la actualidad. Fotografía de la autora.

de nervios, claves y piezas de las portadas de la iglesia Arciprestal de Santa María en Castellón de la Plana.

A pesar del desconocimiento actual de muchos casos, el traslado de edificios históricos fue una actuación mucho más frecuente de lo que se piensa y causó daños irreparables a nuestro patrimonio. No solo se separaba el edificio de su ambiente originario, sino que, al introducirlo en otro ajeno, se aniquilaba parte de su identidad cultural, desligándolo del espacio natural y social para el que había sido creado.

${ }^{36}$ Entre las publicaciones más recientes sobre este tema, es necesario destacar: M. P. GARCÍA CUETOS, "Desmontes, traslados y reconstrucciones de monumentos. Soluciones "excepcionales" y su aplicación metodológica en la restauración del siglo XX en España", en J. DELGADO RODRÍGUEZ, (ed.), De Viollet-le-Duc á Carta de Veneza. Teoría e práctica do restauro no espaço iberoamericano, Lisboa, 2015, pp. 551-558.

${ }^{37}$ B. M. CASTRO FERNÁNDEZ, Francisco Pons-Sorolla. Arquitecto restaurador..., pp. 171-172. 